\title{
Guía de prevención de infecciones y uso de antibióticos profilácticos en endoscopia
}

\author{
Claudia I. Blanco-Vela ${ }^{1,2}$, Mario Peláez-Luna ${ }^{3,4,5 *}$, Clara L. Martínez-García ${ }^{6}$, Jony Cerna-Cardona7, Claudia \\ Martínez-Camacho ${ }^{8}, X_{0}$ chiquetzal Sánchez-Chávez ${ }^{9}$, Ángel Reyes-Dorante ${ }^{10}$, Omar E. rujillo-Benavides ${ }^{11}$, \\ Héctor Espino-Cortés ${ }^{7}$ Óscar Hernández-Mondragón ${ }^{12}$, Félix I. Téllez-Ávila ${ }^{13}$, Diego Angulo-Molina ${ }^{5}$, Mario \\ Zárate-Guzmán ${ }^{14,15}$, Alejandra Noble-Lugo ${ }^{16}$, Francisco Belaunzarán-Zamudio ${ }^{17}$, Rodrigo Soto-Solís ${ }^{12}$, \\ Orlando Bada-Yllán ${ }^{18}$, Irma Hoyo-Ulloa ${ }^{19}$ y Samantha González-Labrada20
}

${ }^{1}$ Servicio de Gastroenterología, Hospital San Ángel Inn Universidad, Ciudad de México; ${ }^{2}$ Servicio de Endoscopia, Hospital Central Militar, Ciudad de México; ${ }^{3}$ División de Investigación, Facultad de Medicina, Universidad Nacional Autónoma de México, Ciudad de México; ${ }^{4}$ Departamento de Gastroenterología, Instituto Nacional de Ciencias Médicas y Nutrición Salvador Zubirán, Ciudad de México; ${ }^{5}$ Unidad de Endoscopia Avanzada, Centro Médico ABC, Ciudad de México; ${ }^{6}$ Servicio Endoscopia, Hospital San Ángel Inn Universidad, Ciudad de México; ${ }^{7}$ Servicio de Endoscopia, Hospital Juárez de México, Ciudad de México; ${ }^{8}$ Servicio de Endoscopia, Hospital General Regional N. ${ }^{\circ}$ Dr. Carlos MacGregor Sánchez Navarro, Ciudad de México; ${ }^{9}$ Servicio de Endoscopia, Hospital Ángeles del Pedregal, Ciudad de México; ${ }^{10}$ Servicio de Gastroenterología, Hospital San Ángel Inn Chapultepec, Ciudad de México; ${ }^{11}$ Servicio de Gastroenterología, Hospital General de Zona 42, Instituto Mexicano del Seguro Social, Puerto Vallarta, Jal.; ${ }^{12}$ Departamento de Endoscopia, Hospital de Especialidades Centro Médico Nacional Siglo XXI, Ciudad de México; ${ }^{13}$ Departamento de Endoscopia, Instituto Nacional de Ciencias Médicas y Nutrición Salvador Zubirán, Ciudad de México; ${ }^{14}$ Servicio de Endoscopia, Hospital General Dr. Eduardo Liceaga, Ciudad de México; ${ }^{15}$ Servicio de Endoscopia, Hospital Ángeles Lomas, Ciudad de México; ${ }^{16}$ Servicio de Gastroenterologia, Hospital Español, Ciudad de México; ${ }^{17}$ Departamento de Infectología, Instituto Nacional de Ciencias Médicas y Nutrición Salvador Zubirán, Ciudad de México; ${ }^{18}$ Servicio de Endoscopia, Hospital General Dr. Manuel Gea González, Ciudad de México; ${ }^{19}$ Departamento de Infectología, Centro Médico ABC, Ciudad de México; ${ }^{20}$ Enfermería, Case Medical Inc., Ciudad de México. México

\section{Resumen}

La endoscopia tiene el riesgo inherente de introducir bacterias en el organismo a través de las membranas mucosas, lo que podría ocasionar bacteriemia y posterior infección. El valor del uso de antibióticos profilácticos en pacientes que requieren procedimientos endoscópicos ha sido objeto de debate y su uso debe considerar el riesgo individual de cada paciente para desarrollar infecciones. La Asociación Mexicana de Endoscopia Gastrointestinal convocó a un grupo de endoscopistas, gastroenterólogos y enfermeros especializados en procesamiento de endoscopios con la finalidad de evaluar de manera crítica la evidencia científica y proponer estrategias para el uso racional de antibióticos mediante un consenso.

Palabras clave: Endoscopia. Antibióticos. Profilaxis. Reprocesamiento.

\section{Clinical Guidelines. Infection prevention and antibiotic prophylaxis in endoscopy}

\begin{abstract}
Endoscopic procedures carry a risk to introduce microorganisms into the bloodstream through the gastrointestinal mucosa, potentially leading to bacteremia or infectious complications. Antibiotic prophylaxis usefulness has been long under debate. Currently, both endoscopic procedure and patient related risk factors should be weighted and individualized before considering antimicrobial prophylaxis. The Asociación Mexicana de Endoscopia Gastrointestinal summoned a group of endoscopists, infectious diseases specialists, endoscopy specialized nursing staff in order to review current scientific evidence and develop guidelines on the utility of antibiotic prophylaxis in endoscopic procedures.
\end{abstract}

Key words: Endoscopy. Antibiotic. Prophylaxis. Preprocessing.

\section{Correspondencia:}

*Mario Peláez-Luna

E-mail: mariopl@ prodigy.net.mx
Fecha de aceptación: 20-02-2020

Fecha de aceptación: 10-03-2020

DOI: 10.24875/END.M20000201
Disponible en internet: 10-09-2020

Endoscopia. 2020;32(3):73-90 www.endoscopia-ameg.com 


\section{Introducción}

La endoscopia es un procedimiento invasivo con riesgo inherente de introducir bacterias en el organismo a través de las membranas mucosas, lo que podría ocasionar bacteriemia y posterior infección. El valor del uso de antibióticos profilácticos en pacientes que requieren procedimientos endoscópicos ha sido objeto de debate debido a la baja incidencia de complicaciones infecciosas asociadas hasta ahora a dispositivos endoscópicos y a la falta de suficientes ensayos clínicos que apoyen el beneficio de la profilaxis antibiótica. El uso de esta estrategia debe considerar el riesgo individual de cada paciente para desarrollar infecciones y/o bacteriemia y ponderarlo con el riesgo de promover el desarrollo de resistencia bacteriana.

Por este motivo, la Asociación Mexicana de Endoscopia Gastrointestinal (AMEG) convocó en marzo del 2019 a un grupo de endoscopistas, gastroenterólogos y enfermeros especializados en procesamiento de endoscopios con la finalidad de evaluar de manera crítica la evidencia científica disponible sobre prevención de infecciones en endoscopia y así proponer estrategias para el uso racional de antibióticos mediante un consenso.

La presente guía se enfoca en la prevención de infecciones y uso de antibióticos profilácticos en endoscopia de acuerdo con lineamientos internacionales y la disponibilidad de recursos humanos y tecnológicos en nuestro país, basándose en la evidencia científica disponible en la actualidad.

\section{Metodología}

Para preparar y realizar la elaboración de guías consensuadas se utilizó el método Delphi'. Se crearon cuatro mesas de trabajo y a cada una se le asignó un tema específico que representa cada una de las secciones de la presente guía. Cuatro de los participantes realizaron una búsqueda en la base de datos PubMed de artículos publicados a manera de resumen o artículo completo en los idiomas inglés y español. Se dio preferencia a revisiones sistemáticas, metaanálisis, guías de práctica clínica, consensos, ensayos clínicos controlados y cohortes, aunque no se limitó a este tipo de artículos.

Una vez concluida la búsqueda se elaboraron enunciados relacionados con el tema de cada mesa y fueron enviados a cada coordinador de mesa junto con la bibliografía seleccionada. Cada coordinador asignó aleatoriamente uno o más enunciados a cada participante, quien calificó la evidencia que los apoya. Para evaluar la calidad de la evidencia publicada y seleccionar los artículos más relevantes sin importar si los resultados eran positivos o negativos se utilizó el sistema GRADE (Grading of Recommendations, Assessment, Development and Evaluation) modificado².

Con la finalidad de homogeneizar la forma de evaluación y que cada participante conociera el método, se les pidió y envió un enlace electrónico para concluir el curso en línea gratuito Up to Date del sistema GRADE. Este sistema tiene el objetivo de mejorar la evaluación de la calidad de la evidencia y la fuerza con la que esta se recomienda. En este sistema, la graduación de la calidad no se basa en el tipo de estudio (diseño y metodología), se consideran también los desenlaces (pertinencia, relevancia, etc.), así como las preguntas elaboradas para estudiar dicho desenlace.

De tal forma que aun cuando la evidencia de mayor calidad se origina en revisiones sistemáticas, ensayos clínicos, etc., el sistema GRADE clasifica la calidad con base en el diseño y métodos utilizados para evaluar los desenlaces preseleccionados o responder una pregunta tipo PICO (Población o Pacientes, Intervención o Indicador, Control o Comparación y O de desenlace por su traducción del inglés Outcome) elaborada con anterioridad y con fines específicos. Esto permite que evidencia de menor calidad (p. ej., casos y controles, estudios transversales, series de casos) pueda ser considerada ${ }^{3}$.

La calidad de la evidencia puede ser alta cuando la seguridad o confianza en los desenlaces o efectos estimados no puede o no podría ser modificada por investigaciones subsecuentes. Se considera moderada cuando investigaciones posteriores podrían modificar los efectos o desenlaces y, por lo tanto, nuestra confianza en la información actual disminuye. La calidad es baja cuando es muy probable que la información actual se modifique con estudios ulteriores y muy baja cuando los desenlaces o efectos en estudio conocidos en la actualidad son extremadamente inciertos (Tabla 1).

La calidad y fuerza de recomendación (débil o fuerte) se expresan como letras mayúsculas de la $A$ a la $D$ (que indican la calidad de evidencia: A para muy alta calidad y $D$ para muy baja calidad) y números (que indican la fuerza de recomendación a favor o en contra: 1 fuerte y 2 débil) (Tabla 2).

Estos enunciados y su calificación fueron presentados por los coordinadores a los miembros de sus mesas, donde se revisó su contenido y redacción efectuando modificaciones en conjunto, además de discutir la pertinencia o necesidad de eliminar o agregar 
Tabla 1. Evaluación GRADE (Grading of

Recommendations, Assessment, Development and Evaluation)

\begin{tabular}{|l|l|}
\hline $\begin{array}{l}\text { Niveles de } \\
\text { calidad }\end{array}$ & Definición \\
\hline Alto & $\begin{array}{l}\text { Alta confianza en la coincidencia entre el } \\
\text { efecto real y el estimado }\end{array}$ \\
\hline Moderado & $\begin{array}{l}\text { Moderada confianza en la estimación del } \\
\text { efecto. Hay posibilidad de que el efecto real } \\
\text { esté alejado del efecto estimado }\end{array}$ \\
\hline Bajo & $\begin{array}{l}\text { Confianza limitada en la estimación del efecto. } \\
\text { El efecto real puede estar lejos del estimado }\end{array}$ \\
\hline Muy bajo & $\begin{array}{l}\text { Poca confianza en el efecto estimado. El } \\
\text { efecto verdadero muy probablemente sea } \\
\text { diferente del estimado }\end{array}$ \\
\hline
\end{tabular}

otros enunciados. Se votó «en acuerdo» 0 «en desacuerdo" para cada enunciado. Cuando el acuerdo fue mayor al $75 \%$ se concluyó que el enunciado permanecería sin modificaciones, y cuando el acuerdo fue menor al $75 \%$ se realizaron modificaciones en contenido y redacción sometiéndose nuevamente a votación, y así sucesivamente hasta llegar a un acuerdo mayor al $75 \%$.

Aquellos enunciados con desacuerdo mayor del $75 \%$, repetidos o redundantes fueron eliminados del proceso. Posteriormente a la reunión cada coordinador y los miembros de cada mesa desarrollaron comentarios y consideraciones finales a cada enunciado, además de revisar y determinar el nivel y calidad de evidencia que lo apoya, así como la fortaleza de la recomendación, basados en el sistema GRADE modificado antes mencionado (Tabla 2).

Esta guía puede y deberá ser revisada y editada periódicamente de acuerdo con la necesidad de incorporar cambios y avances tecnológicos, así como información nueva y relevante. Las recomendaciones presentadas y fuerza de estas se basan en la revisión de la evidencia científica disponible al momento de su elaboración, así como en la discusión y evaluación de los riesgos y beneficios hecha por los participantes de la guía. Es importante recordar que esta, como todas las guías, presenta información que pretende ayudar a los involucrados en el cuidado de pacientes y no debe considerarse como reglas ni estándares de cuidado inmodificables, puesto que las decisiones clínicas deben individualizarse y suelen ser resultado de un análisis detallado de la situación clínica del paciente y recursos disponibles que pudieran o no estar en acuerdo con este documento.

\section{Definiciones}

- Translocación bacteriana: es la migración de microorganismos viables $y / 0$ productos microbianos (endotoxinas, ADN bacteriano, etc.) a través de la mucosa anatómicamente íntegra desde la luz de cualquier parte del tubo digestivo a sitios extraintestinales ${ }^{4-7}$.

- Bacteriemiea. Es el paso y presencia transitoria de bacterias al torrente sanguíneo $0^{4-8}$.

- Infección clínicamente significativa. Es la invasión y multiplicación de microorganismos como bacterias, virus y parásitos que normalmente no están presentes en alguna parte del organismo asociadas a la presencia de síntomas (datos de respuesta inflamatoria sistémica) $)^{4-8}$.

- Profilaxis antibiótica. Es la administración de antibióticos periprocedimiento con el objetivo de prevenir infecciones ${ }^{8}$.

- Evento adverso. Un evento adverso es un daño no intencionado causado al paciente derivado de un acto médico más que por el proceso patológico en si $^{9-10}$.

- Factor de riesgo. Es toda circunstancia o situación que incrementa la probabilidad de una persona de contraer una enfermedad, sufrir una lesión o cualquier otro problema de salud ${ }^{4}$.

- Limpieza. Es el proceso de eliminación física de material orgánico y/o detritos, generalmente mediante el uso de agua con detergentes. Está diseñado para retirar organismos más que para matarlos ${ }^{11}$.

- Desinfección. Es el proceso que erradica la mayoría de los microorganismos y se realiza comúnmente mediante el uso de germicidas químicos líquidos. Existen tres niveles de desinfección según el grado de eliminación microbiana implicado: 1) desinfección de alto nivel (DAN), que destruye microorganismos vegetativos, micobacterias, hongos, virus pequeños o no lipídicos y virus medianos o lipídicos, pero no necesariamente un gran número de esporas bacterianas; 2) desinfección de nivel intermedio (DIN), que elimina microrganismos vegetativos, incluidos micobacterias y hongos, e inactiva a la mayoría de los virus; 3) desinfección de nivel bajo (DBN), que inactiva la mayoría de las bacterias vegetativas (excepto micobacterias), algunos hongos y virus ${ }^{11,12}$. 
Tabla 2. Recomendaciones GRADE (Grading of Recommendations, Assessment, Development and Evaluation)

\section{Grado de recomendación}

$1 \mathrm{~A}$.

Recomendación

fuerte/calidad de evidencia alta

$1 \mathrm{~B}$.

Recomendación fuerte/calidad de evidencia moderada

1C.

Recomendación fuerte /calidad de evidencia baja

$2 A$.

Recomendación

débil con

evidencia de

calidad alta

$2 B$.

Recomendación

débil/calidad de

evidencia

moderada

2C.

Recomendación

débil/ calidad de evidencia baja

\section{Claridad del riesgo/beneficio}

Los beneficios claramente superan los riesgos o viceversa

Los beneficios claramente superan los riesgos o viceversa. Existe incertidumbre en los estimados de riesgo y beneficio

Los beneficios aparentemente superan los riesgos o viceversa

Los beneficios están equilibrados o son similares respecto a los riesgos

Evidencia consistente proveniente de ensayos

Los beneficios están equilibrados o son similares respecto a los riesgos. Existe incertidumbre en los estimados de riesgo y beneficio

Incertidumbre en los estimados de riesgo y beneficio. Los beneficios posiblemente están equilibrados o son similares respecto a los riesgos
Evidencia consistente proveniente de ensayos controlados y aleatorizados o bien evidencia convincente de alguna otra forma. Estudios posteriores difícilmente impactarán nuestra confianza y cambiaran el estimado de los riesgos y beneficios

Evidencia de ensayos clínicos controlados con limitaciones importantes (resultados inconsistentes, fallas metodológicas o imprecisiones) o evidencia muy fuerte de estudios con otro diseño. Investigaciones futuras (si se realizan) pueden impactar en la confianza y modificar los beneficios y riesgos estimados

Evidencia de estudios observacionales, experiencia clínica no sistematizada o de ensayos clínicos controlados con errores serios. Cualquier estimación de riesgo o beneficio es incierta controlados y aleatorizados o bien evidencia convincente de alguna otra forma. Estudios posteriores difícilmente impactarán en nuestra confianza y cambiaran el estimado de los riesgos y beneficios

Implicaciones

Las recomendaciones fuertes pueden aplicarse a todos los casos en casi todas las circunstancias

Recomendación fuerte que podría aplicarse a todos los casos en casi todas las circunstancias a menos que exista una alternativa clara, congruente y racional

La recomendación fuerte puede aplicarse a casi todos los pacientes, pero la evidencia que la apoya es de baja calidad

La recomendación débil implica que la mejor acción o estrategia puede cambiar dependiendo de las circunstancias clínicas y sociales de cada caso

Evidencia de ensayos clínicos controlados con Recomendación débil. limitaciones importantes (resultados inconsistentes, Manejos alternativos fallas metodológicas o imprecisiones) 0 evidencia pueden considerarse muy fuerte de estudios con otro diseño. Investigaciones futuras (si se realizan) pueden impactar en la confianza y modificar los beneficios y riesgos estimados

Evidencia de estudios observacionales, experiencia clínica no sistematizada o de ensayos clínicos controlados con errores serios. Cualquier estimación de riesgo o beneficio es incierto mejores en algunos pacientes y bajo ciertas circunstancias

Recomendación muy débil. Otras alternativas pudieran ser igualmente razonables
- Esterilización. Es el proceso que elimina todos los microbios, incluidas las esporas bacterianas ${ }^{11}$.

\section{Procedimientos endoscópicos de alto y bajo riesgo de bacteriemia e infección}

\section{Procedimientos endoscópicos diagnósticos de tubo digestivo}

La tasa de bacteriemia de una endoscopia diagnóstica de tubo digestivo alto con o sin biopsia se estima que es del 4\%; cuando se presenta suele ser leve y de corta duración, sin consecuencias clínicas mayores. La tasa de bacteriemia asociada a colonoscopia se ha estimado en un $4.4 \%{ }^{13}$. No existen aún reportes sobre la bacteriemia en enteroscopia (monobalón, doble balón o espiral), pero se piensa que debe ser comparable a exámenes endoscópicos ordinarios ${ }^{14}$. Dado que la frecuencia de bacteriemia es relativamente baja y se asocia a una menor tasa de infección, no se recomienda el uso sistemático de profilaxis con antibióticos (Tabla 3).

\section{Posicionamiento}

La AMEG recomienda que no se utilicen antibióticos profilácticos en los procedimientos endoscópicos 
diagnósticos. Recomendación fuerte, nivel de evidencia bajo (GRADE 1C).

\section{Procedimientos endoscópicos terapéuticos de tubo digestivo}

Existen procedimientos endoscópicos terapéuticos que teóricamente conllevan un riesgo elevado de infecciones asociadas al mismo procedimiento (Tabla 4). El riesgo de bacteriemia de una dilatación esofágica se estima entre 12 y el $22 \%$ de acuerdo con tres estudios prospectivos en los cuales no se utilizaron antibióticos profilácticos. En los tres estudios se incluyeron únicamente pacientes con dilataciones realizadas con bujía. Se observó que los cuadros de bacteriemia fueron más frecuentes en pacientes con estenosis malignas $(52.9 \text { vs. } 15 \%)^{14,15}$.

La escleroterapia de várices esofágicas tiene una tasa de bacteriemia estimada de $14.6 \%$ (intervalo: $0-52.5 \%$ ), mientras que en la ligadura de varices esofágicas la incidencia estimada es de $3-6 \%{ }^{13}$. En un metaanálisis de 19 estudios prospectivos que incluyen 1,001 procedimientos en 587 pacientes con cirrosis y várices esofágicas, la frecuencia de bacteriemia posterior a terapia endoscópica de várices fue del 13\%. La frecuencia de bacteriemia en pacientes sometidos a escleroterapia fue mayor (17\%) comaprada con la observada $(6 \%)$ en pacientes tratados mediante ligadura $(p=0.106)$. La incidencia de bacteriemia es baja en pacientes con cirrosis sometidos a escleroterapia o ligadura, sin sangrado activo, por lo que no se recomienda profilaxis con antibióticos ${ }^{16}$.

\section{Posicionamiento}

La AMEG recomienda no administrar antibióticos profilácticos en pacientes a quienes se les realizará dilatación endoscópica. Recomendación fuerte, nivel de evidencia bajo (GRADE 1C).

La AMEG recomienda no administrar antibióticos profilácticos en los pacientes sometidos a tratamiento endoscópico de várices esofágicas sin sangrado. Recomendación fuerte, nivel de evidencia alto (GRADE 1A).

\section{Riesgo de bacteriemia e infección por accesos enterales percutáneos endoscópicos}

La realización de gastrostomía percutánea endoscópica (PEG, por sus siglas en inglés) se considera un
Tabla 3. Procedimientos asociados con bajo y alto riesgo de bacteriemia ${ }^{1-20}$

\begin{tabular}{l} 
Bajo riesgo de bacteriemia \\
\hline \multicolumn{1}{c}{ Procedimiento } \\
\hline Endoscopia alta con o sin biopsias con pinza \\
Colonoscopia con o sin biopsias con pinza \\
\hline Polipectomía mediante resección endoscópica de la mucosa \\
\hline Sigmoidoscopia \\
\hline Colocación endoprótesis sin dilatación \\
\hline Disección endoscópica de la submucosa \\
\hline Miotomía endoscópica peroral \\
\hline Resección endoscópica de la mucosa \\
\hline Obliteración electiva de várices gástricas con cianocrilato \\
\hline Ligadura electiva de várices esofágicas \\
\hline Ultrasonido endoscópico con o sin BAAF \\
\hline Alto riesgo de bacteriemia \\
\hline Colangiografía retrógrada endoscópica con instrumentación de \\
\hline Cola biliar
\end{tabular}

BAAF: biopsia por aspiración con aguja fina.

Adaptada de Fink, et al., 1984' Guyatt, et al, 20083. Giannelli, et al., 2014; Ponziani, et al., 20185; Ravinder, et al., 20176; Wiest, et al., 2014 ; ASGE Standards of Practice Committee, 2015 ; Fernández Catón, 2015'; ASGE Standards of Practice Committee, 201210; ASGE Quality Assurance in Endoscopy Committee, 2018 11; World Health Organization, 200412; Nelson, 2003'3; Nelson, et al., 199814; Zuccaro, et al., 199815;

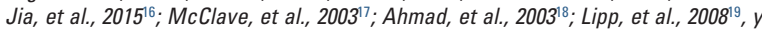
Kayal, et al., $2018^{20}$

Tabla 4. Procedimientos asociados a riesgo de infección que se benefician de profilaxis antibiótica

\begin{tabular}{l} 
Procedimiento \\
\hline $\begin{array}{l}\text { Colangiografía endoscópica con drenaje incompleto de vía } \\
\text { biliar }\end{array}$ \\
\hline Colangioscopia con toma de biopsias \\
Aspiración con aguja fina de quistes mediastinales \\
(procedimiento no recomendado por alta mortalidad) \\
Aspiración con aguja fina de quistes de páncreas \\
Colocación de sondas de alimentación endoscópica percutánea
\end{tabular}


procedimiento seguro, sin embargo la tasa y tipo de complicaciones es variable, según la población de estudio; la más frecuente es la infección periestomal, cuya prevalencia varía entre 5 y $30 \%$ de acuerdo con lo reportado en los diversos estudios ${ }^{17}$.

Ahmad, et al..$^{18}$ analizaron prospectivamente 102 pacientes a quienes se les realizó PEG, 66 pacientes se asignaron aleatoriamente al grupo uno, en el que 33 recibieron cefuroxima profiláctica y 33 placebo; los 36 pacientes restantes que estaban recibiendo tratamiento antibiótico fueron asignados al grupo 2. En el análisis por protocolo los antibióticos redujeron significativamente la incidencia de infección periestomal tanto en la profilaxis, $(3 \%)$, como en el tratamiento con antibiótico, (2.8\%), comparado comparado con el observado en el grupo placebo (18\%; Intervalo de confianza 95\% [IC95\%]: 4-31; $p=0.04$ ), concluyendo que la profilaxis antibiótica, al igual que la administración simultánea de antibióticos al momento de colocar la PEG, reduce la infección periestomal.

Lipp, et al. ${ }^{19}$ demostraron en una revisión sistemática la utilidad de la profilaxis con antibióticos en pacientes en los que se realiza PEG con técnica de pull o tracción. El metaanálisis incluyó 1,100 pacientes, de los cuales $584(53 \%)$ recibieron profilaxis y 516 pacientes $(47 \%)$ placebo. El grupo de profilaxis recibió una dosis de cefalosporina intravenosa 30 minutos antes de realizar la PEG. Se observó una reducción estadísticamente significativa de la incidencia de infección periestomal con la profilaxis de antibióticos comparada con placebo ( 8.7 vs. $26 \%$ respectivamente; razón de momios [RM]: de 0.31; IC 95\%: 0.22-0.44); el número de pacientes necesario que tratar (NNT) para evitar una infección fue de 5.8 pacientes.

En otro estudio retrospectivo en 781 pacientes a quienes se les colocó PEG con técnica de pull, que recibieron profilaxis con ceftazidima $1 \mathrm{~g}$ intravenosa 1 hora previa al procedimiento, se observó infección periestomal en el $22 \%$. En el análisis multivariado de este grupo de pacientes se reportó que la radioterapia antes de realizar la PEG (RM: 5.9; IC 95\%: 2.8-12.1), la diabetes mellitus (RM: 5.2; IC 95\%: 3.6-7.5) y la albúmina sérica < $3.5 \mathrm{mg} / \mathrm{dl}$ (RM: 4.9; IC 95\%: 3.4-7.1) son factores de riesgo independientes para infección periestomal $^{20}$.

El tipo de antibióticos profilácticos que administrar para reducir la infección periestomal en la PEG deberá elegirse de acuerdo con la información microbiológica local. No hay estudios del papel de los antibióticos profilácticos antes de la realización de yeyunostomía percutánea endoscópica, sin embargo podría ser similar a lo observado en pacientes con PEG ${ }^{8}$.

\section{Posicionamiento}

La AMEG recomienda el uso de antibióticos profilácticos de 30 a 60 minutos antes de la PEG con técnica de tracción. La selección del antibiótico dependerá de la epidemiología hospitalaria. Recomendación fuerte, nivel de evidencia moderado (GRADE 1B).

\section{Riesgos de bacteriemia e infección asociados a colangiopancreatografía retrógrada endoscópica}

La colangiopancreatografía retrógrada endoscópica (CPRE) con drenaje de la vía biliar es el tratamiento de elección de la colangitis aguda. Existe probablemente un riesgo alto de bacteriemia con la instrumentación de la vía biliar, pero un riesgo bajo de infección secundaria. El riesgo de bacteriemia reportado es del $6.4 \%$ y aumenta hasta el $18 \%$ en casos de obstrucción biliar por cálculos o estenosis. El riesgo de infección se estima entre el 0.5 y el $3 \%$ (con y sin antibióticos profilácticos, respectivamente) ${ }^{13}$.

Aunque el uso de antibióticos profilácticos ha demostrado disminuir la incidencia de bacteriemia asociada a la CPRE, no hay estudios que demuestren que previene la colangitis. Un metaanálisis de cinco estudios aleatorizados con placebo ${ }^{21}$ reportó que el uso sistemático de antibióticos profilácticos antes de la CPRE no disminuye el riesgo de colangitis o sepsis (riesgo relativo [RR]: 0.91; IC 95\%: 0.39-2.15).

Se obtuvieron conclusiones semejantes en otro metaanálisis de siete estudios y 1,389 pacientes que reportó mayor incidencia de colangitis post-CPRE electiva en controles ( $n=705$ ), comparada con aquellos que recibieron profilaxis antibiótica $(n=684)$ (5.8 vs. $3.4 \%$ respectivamente) sin diferencia estadísticamente significativa (RR: 0.58; IC 95\%: 0.22-1.55) y NNT de 38 para prevenir un episodio de colangitis ${ }^{22}$.

Son factores de riesgo para desarrollar colangitis secundaria a la CPRE: el drenaje incompleto de la vía biliar, pacientes postrasplante hepático, aquellos con colangitis esclerosante primaria o con tumores hiliares; todos ellos casos en los que parece prudente usar antibióticos profilácticos. En caso de no lograr un drenaje completo se debe iniciar esquema antibiótico terapéutico y realizar o completar el drenaje de la vía biliar mediante otro método lo antes posible ${ }^{23,24}$. Con la colangioscopia se ha reportado bacteriemia en el 
$8.8 \%$ y colangitis en el $7 \%$, siendo más frecuente con la toma de biopsia $(p=0.035)^{25}$.

\section{Posicionamiento}

La AMEG recomienda no administrar profilaxis con antibióticos cuando se anticipa un drenaje completo de la vía biliar. Recomendación fuerte, nivel de evidencia alto (GRADE 1A).

La AMEG recomienda profilaxis en pacientes sometidos a CPRE con factores de riesgo de colangitis. Deben usarse antibióticos que cubran la flora biliar gramnegativa y enterococos y continuarlos después del procedimiento si el drenaje biliar es incompleto. Se recomienda no utilizar quinolonas en profilaxis. Recomendación fuerte, nivel de evidencia moderado (GRA$D E$ 1B).

La AMEG recomienda administrar antibióticos profilácticos en pacientes sometidos a colangioscopia con toma de biopsias. Recomendación fuerte, nivel de evidencia moderado (GRADE 1B).

\section{Procedimientos de ultrasonido endoscópico con riesgo de bacteriemia e infección}

Existe un amplio número de procedimientos que se pueden realizar por ultrasonido endoscópico (USE) y afortunadamente la gran mayoría de ellos no representa un riesgo para el desarrollo de bacteriemia o infección, a excepción de aquellos en los que se realizará toma de biopsias (lesiones sólidas y quísticas). En el drenaje de colecciones peripancreáticas o de la vía biliar la profilaxis no aplica, ya que el uso de antibióticos es con fines terapéuticos.

En la punción de lesiones sólidas o adenopatías los riesgos son inexistentes y no se recomienda utilizar antibióticos profilácticos ${ }^{26,27}$. Una duda razonable es si estos riesgos cambian cuando la toma de biopsias se realiza a través de la mucosa colónica o bien se toman de lesiones dependientes del tubo digestivo bajo. Un estudio prospectivo ${ }^{28}$ de 563 casos mostró que la tasa de infecciones fue similar tanto con el uso $(n=91)$ como con la no administración $(n=472)$ de antibióticos profilácticos (1.1 y $1 \%$, respectivamente; $p=0.91$ ). Se debe mencionar que el uso de antibióticos en este estudio fue a consideración del endoscopista.

En casi todos los estudios en donde se hace referencia a la punción de lesiones quísticas se administran antibióticos profilácticos, sin embargo dicha administración no es uniforme en cuanto al tipo de antibióticos utilizados y su posología. En general, los antibióticos pueden ser administrados inicialmente por vía intravenosa de 30-60 minutos antes del estudio, justo antes del estudio o durante el estudio con esquemas que se continúan de manera oral por 3-7 días. Los estudios que sugieren que una sola dosis es suficiente no son comparativos ${ }^{29-31}$. Un estudio prospectivo ${ }^{29}$ reportó una incidencia de infecciones del $0 \%$ en los pacientes con uso de antibióticos profilácticos, sin embargo no se utilizó un grupo control y el número de pacientes evaluados fue bajo $(n=80)$.

Un estudio retrospectivo comparativo no encontró beneficios con el uso de antibióticos profilácticos en pacientes con lesiones quísticas. La frecuencia de complicaciones mayores y menores en el grupo con uso de antibióticos $(n=88)$ fue del 2.3 y el $6.8 \%$ respectivamente comparado con las observadas en el grupo sin antibióticos, 2.2 y $4.5 \%$ ( $p=1.0$ y $p=0.56$, respectivamente). En dicho estudio los antibióticos utilizados fueron a discreción del endoscopista (levofloxacino en el $89 \%$ de los casos, combinación de ciprofloxacino y metronidazol en tres casos, vancomicina más gentamicina en dos casos, piperacilina-tazobactam en dos casos, y un solo caso con amoxicilina-clavulánico más metronidazol, ampicilina 0 doxiciclina) ${ }^{32}$.

\section{Posicionamiento}

La AMEG recomienda que no se administren antibióticos profilácticos en los casos de toma de biopsia de lesiones sólidas guiadas por USE. Recomendación fuerte, nivel de evidencia bajo (GRADE 1C).

La AMEG sugiere el uso de antibióticos profilácticos en los casos de punción de lesiones quísticas guiada por USE. En la actualidad se sugiere no usar quinolonas con fines profilácticos. Recomendación débil, nivel de evidencia bajo (GRADE 2C).

\section{Riesgo de bacteriemia e infección en disección endoscópica de la submucosa y resección endoscópica de la mucosa}

La resección endoscópica de la mucosa (REM) y la disección endoscópica submucosa (DES) son procedimientos cada vez más comunes ${ }^{33}$. Debido al mayor tiempo del procedimiento, el tamaño de las lesiones resecadas y el volumen de solución inyectado en la submucosa se piensa que la DES tiene una mayor prevalencia de bacteriemia comparada con la REM, sin 
embargo la prevalencia en general es $<5 \%$ y sin significado clínico en la mayoría de los $\operatorname{casos}^{34}$.

Lee, et al. ${ }^{35}$ evaluaron el riesgo de bacteriemia mediante hemocultivos obtenidos posterior a la realización de REM con capuchón en 38 paciente ( 25 gástricas, 11 esofágicas y 2 duodenales). El $5.4 \%$ de los hemocultivos fue positivo a los 10 min posteriores al procedimiento, pero todos fueron negativos a las 4 horas de haber finalizado. No se reportaron datos clínicos de sepsis o infección.

Min, et al. ${ }^{36}$ estudiaron la incidencia de bacteriemia en 40 pacientes posterior a la realización de REM o DES en colon, documentando un $2.5 \%$ de bacteriemia a las 2 horas posteriores al procedimiento, sin repercusiones clínicas. Por su parte, Itaba, et al..$^{37}$ documentaron un $4.4 \%$ de bacteriemia a los 10 min posteriores a la realización de DES y ningún paciente fue positivo a las 3 horas de haberla finalizado, además no se presentó algún tipo de traducción clínica. La edad tampoco afecta la incidencia de bacteriemia de acuerdo con Doyama, et al. ${ }^{38}$, posterior a comparar dos poblacionales distintas ( $\geq 80$ vs. $<80$ años; 2.4 vs. $2.8 \%$; $\sin$ significación estadística).

La evidencia sugiere que la frecuencia de bacteriemia posterior a un procedimiento de DES es baja, transitoria y no genera riesgo de complicaciones al paciente, por lo tanto, no se justifica la administración profiláctica de antibióticos. La frecuencia de bacteriemia en REM también es baja (4\%), siendo el colon el sitio con mayor prevalencia (2-4\%) sobre todo en pacientes con preparación intestinal inadecuada al momento del procedimiento ${ }^{8}$.

\section{Posicionamiento}

La AMEG recomienda no administrar antibióticos profilácticos previos a la realización de DES o REM. Recomendación fuerte, nivel de evidencia moderado (GRADE 1B).

\section{Condiciones médicas con riesgo incrementado de presentar bacteriemia e infección derivada de un procedimiento endoscópico}

\section{Endocarditis infecciosa}

No existen estudios prospectivos para determinar el valor del uso de antibióticos profilácticos contra la endocarditis durante la endoscopia gastrointestinal. Los pocos estudios disponibles muestran importantes variaciones en el intervalo de tiempo entre endoscopia y la aparición de síntomas, por lo que no ha sido posible determinar con certeza si la endocarditis fue causada por el procedimiento o por una bacteriemia incidental no relacionada.

Las directrices actuales sobre la prevención, diagnóstico y tratamiento de la endocarditis infecciosa (ACC/AHA, Colegio Americano de Cardiología/Asociación Americana del Corazón 2008 y pautas ESC, de la Sociedad Europea de Cardiología) no recomiendan profilaxis antimicrobiana previa a una endoscopia y colonoscopia en ausencia de infección activa ${ }^{39-42}$.

Existen condiciones cardiacas asociadas a un mayor riesgo de endocarditis infecciosa en los cuales podría considerarse el uso de antibióticos profilácticos, como: dispositivos protésicos/válvulas cardiacas (mecánicos o bioprotésicos), antecedente de endocarditis infecciosa, trasplante cardiaco, valvulopatía cardiaca y en pacientes con cardiopatía congénita (Tabla 5). La endocarditis infecciosa puede aparecer en pacientes sin enfermedad cardiaca valvular y en estos debe considerarse la existencia de neoplasia maligna oculta. ${ }^{42-44}$

\section{Posicionamiento}

La AMEG recomienda no administrar antibióticos profilácticos para endocarditis previo a un procedimiento endoscópico excepto en casos portadores de condiciones cardiacas como: dispositivos protésicos/válvulas cardiacas (mecánicos o bioprotésicos), antecedente de endocarditis infecciosa, trasplante cardiaco, valvulopatía cardiaca y cardiopatía congénita. Recomendación fuerte, nivel de evidencia moderado (GRADE 1B).

\section{Prótesis ortopédicas}

El único estudio prospectivo que evaluó el riesgo de desarrollar infección de prótesis ortopédicas hasta dos años después de algún procedimiento endoscópico gastrointestinal comparó 339 casos hospitalizados por infección de prótesis de rodilla o cadera con controles que ingresaron por un proceso no infeccioso. Los casos y controles fueron sometidos a 187 procedimientos, que incluyeron endoscopia superior, colonoscopia y sigmoidoscopia con o sin biopsia, además de endoscopia con dilatación esofágica. Se estableció un riesgo significativo de infección protésica después de una endoscopia con biopsia de 2.8 (IC 95\%: 1.1-7.1; $p=0.03)^{45}$.

Tras observar las características clínicas de los grupos fue evidente que la frecuencia de diabetes mellitus e inmunocompromiso fue mayor en el grupo de casos. Además, los microorganismos que habitualmente 
Tabla 5. Factores de riesgo asociados al paciente

\begin{tabular}{|c|c|c|c|}
\hline Factores de riesgo asociados al paciente & Factores agregados & $\begin{array}{l}\text { Condición que se } \\
\text { pretende prevenir }\end{array}$ & $\begin{array}{l}\text { Calidad de } \\
\text { evidencia }\end{array}$ \\
\hline $\begin{array}{l}\text { Pacientes con cardiopatías } \\
\text { 1. Prótesis valvular cardiaca } \\
\text { 2. Antecedente de endocarditis infecciosa } \\
\text { 3. Receptores de trasplante cardiaco que desarrollaron } \\
\text { valvulopatía } \\
\text { 4. Enfermedad cardiaca congénita } \\
\text { 5. Enfermedad cardiaca congénita cianótica no reparada } \\
\text { 6. Enfermedad cardiaca congénita reparada con material } \\
\text { protésico o dispositivo colocado quirúrgicamente o por } \\
\text { catéter durante los primeros } 6 \text { meses } \\
\text { 7. Enfermedad cardiaca congénita reparada con defectos } \\
\text { residuales en el sitio o adyacente al sitio protésico }\end{array}$ & $\begin{array}{l}\text { Infección gastrointestinal activa } \\
\text { (p. ej., colangitis })^{*} 0 \\
\text { procedimiento de alto riesgo de } \\
\text { bacteriemia }\end{array}$ & Endocarditis infecciosa & Baja \\
\hline Pacientes con diálisis peritoneal & Colonoscopia & Peritonitis & Baja \\
\hline Pacientes con cirrosis & Hemorragia de tubo digestivo & $\begin{array}{l}\text { Infecciones y } \\
\text { mortalidad }\end{array}$ & Alta \\
\hline Receptores de trasplante hepático ortotópico & & Colangitis & Baja \\
\hline $\begin{array}{l}\text { Pacientes con neutropenia severa }(<500) \text { o neoplasia } \\
\text { hematológica avanzada }\end{array}$ & $\begin{array}{l}\text { Procedimiento endoscópico de } \\
\text { alto riesgo de bacteriemia }\end{array}$ & Infecciones & Baja \\
\hline
\end{tabular}

Prótesis ortopédicas

Lesión sólida de tubo digestivo

Obstrucción de la vía biliar con drenaje completo

*Cobertura contra enterococos.

colonizan el tracto intestinal (estreptococos, enterococos, bacterias gramnegativas y anaerobios) fueron encontrados solo en el $17 \%$ de los casos de infección articular protésica ${ }^{46}$.

En otro estudio, 1,000 pacientes que recibieron 1,112 reemplazos articulares fueron seguidos prospectivamente durante seis años. Durante el seguimiento, el $22 \%$ se sometió a algún procedimiento dental o quirúrgico y el $24 \%$ de ellos presentaron infecciones respiratorias, urinarias o en múltiples sitios; solo ocurrieron tres casos de infección hematógena en el sitio de reemplazo articular, todos pertenecientes a un grupo que presentó ulceración e infección recurrente de la piel que pudo ocasionar bacteriemia crónica (dos de ellos tenían antecedente de artritis reumatoide). Estos resultados sugieren que no es probable que la bacteriemia transitoria asociada a un procedimiento endoscópico infecte una articulación reemplazada en pacientes por lo demás sanos $^{47}$.

No existen estudios que evalúen el riesgo de infección de prótesis ortopédicas en procedimientos gastrointestinales considerados de alto riesgo para bacteriemia como dilatación de estenosis esofágicas, biopsia por ultrasonido endoscópico y colangiografía retrógrada (Tabla 3); sin embargo, la frecuencia de bacteriemia es menor al $22 \%$ en estos casos en comparación con actividades de la vida diaria como cepillarse los dientes o uso de hilo dental, con una incidencia de bacteriemia de hasta el $68 \%{ }^{48}$.

\section{Posicionamiento}

La AMEG no recomienda la administración de antibióticos profilácticos previo procedimiento endoscópico ante la presencia de prótesis ortopédicas. Recomendación fuerte, nivel de la evidencia bajo (GRADE 1B).

\section{Diálisis peritoneal continua ambulatoria}

El desarrollo de peritonitis en pacientes bajo tratamiento con diálisis peritoneal continua ambulatoria (DPCA) es un evento asociado con aumento en costos de tratamiento ${ }^{48}$, importante morbilidad e incluso mortalidad ${ }^{49,50}$ de hasta un $5 \%{ }^{51}$. 
Cuando la peritonitis es por bacterias gramnegativas (como aquellas de origen enteral) se asocia con un peor pronóstico ${ }^{49}$. Los pacientes con DPCA presentan un riesgo mayor de peritonitis posterior en caso de bacteriemia asociada a un procedimiento endoscópico en comparación con sujetos sanos, pues el riesgo de colonización del líquido peritoneal es mayor por su alto contenido de glucosa ${ }^{8,48-50,53}$.

Adicionalmente se debe considerar que los pacientes con enfermedad renal presentan alteraciones en la inmunidad sistémica y en los mecanismos de defensa locales a nivel peritoneal, lo que incrementa su riesgo a infecciones ${ }^{49,53}$.

A pesar de que la evidencia sobre el desarrollo de peritonitis posterior a un procedimiento endoscópico en los pacientes con DPCA proviene en su mayoría de reportes de caso o estudios observacionales retrospectivos, diferentes guías internacionales como las de la American Society for Gastrointestinal Endoscopy (ASGE) $^{8}$ y las de International Society of Peritoneal Dialysis (ISPD) ${ }^{50,52,54}$ sugieren el uso de antibióticos profilácticos en estos pacientes, además de extraer el total del líquido peritoneal previo a cualquier procedimiento endoscópico.

Un estudio retrospectivo ${ }^{53}$ de 77 pacientes en DPCA sometidos a 97 colonoscopias se encontró una incidencia de peritonitis del $6.3 \%$ en aquellos que no recibieron antibiótico profiláctico, mientras que ninguno de los que recibió profilaxis antimicrobiana o antibiótico por otras razones la presentó $(p=0.58)$. En este estudio la toma de biopsias y la polipectomía no se asociaron con un riesgo mayor de peritonitis $(p=0.67 \mathrm{y}$ $p=0.64$ respectivamente comparado con los sujetos a quienes no se les realizó la intervención).

Otro estudio retrospectivo ${ }^{55}$ realizado en 45 pacientes en DPCA en quienes se llevaron a cabo 125 procedimientos endoscópicos reportó una frecuencia global de peritonitis a las 24 horas del $6.4 \%$. En ninguno de los procedimientos que recibieron antibiótico se presentó peritonitis $(n=26)$ comparado con el $8.1 \%$ de los 99 procedimientos que no lo recibieron $(p=0.20)$. Al realizar un subanálisis se observó que los pacientes sometidos a procedimientos endoscópicos distintos a endoscopia superior (grupo no-esofagogastroduodenoscopia [EGD]) tuvieron una frecuencia mayor de peritonitis en comparación con aquellos a quienes se les realizó únicamente endoscopia superior (15.9 vs. 1.2\%; $p<0.005)$. Al analizar solo a pacientes en el grupo no-EGD, el antibiótico profiláctico redujo el riesgo de peritonitis ( 0 vs. $25 \%$; $p<0.005$ ), particularmente cuando se realizaron intervenciones como toma de biopsias o polipectomía ( 0 vs. $53.8 \% ; p<0.05)^{55}$. Este mismo estudio no encontró peritonitis posprocedimiento en los sujetos a quienes se les realizó endoscopia superior diagnóstica, mientras que cuando la endoscopia superior se acompañaba de algún procedimiento (35/81) como biopsias, ligadura variceal y hemostasia, la frecuencia de peritonitis fue del $1.2 \%$ y correspondió a un caso en que se realizó hemostasia por inyección.

Se considera que el riesgo de infección asociado a endoscopia superior es menor debido al efecto bactericida del ácido gástrico y a una menor tasa de translocación bacteriana probablemente relacionada con menor carga bacteriana a este nivel y una pared más gruesa de ese segmento del tracto gastrointestinal ${ }^{55}$.

Un estudio prospectivo aleatorizado ${ }^{56}$ de 93 pacientes de DPAC sometidos a colonoscopia mostró una menor incidencia de peritonitis en 46 pacientes que recibieron antibióticos profilácticos $(6.5 \%)$ vs. 47 pacientes sin antibiótico (8.5\%) ( $p=0.2742)$. El análisis multivariante no demostró aumento del riesgo de peritonitis en caso de polipectomía o toma de biopsias, así como tampoco por la presencia de diverticulosis de colon. El único factor de riesgo independiente para desarrollo de peritonitis fue la presencia de diabetes mellitus (RM: 17), sin diferencias entre el grupo que recibió antibiótico profiláctico y el que no lo recibió 56 .

La evidencia disponible para recomendar el empleo de antibiótico profiláctico previo a un procedimiento endoscópico en pacientes con DPCA es insuficiente y proviene de estudios con limitaciones metodológicas importantes ${ }^{50}$; sin embargo, en los tres estudios referidos previamente el $50 \%$ de los casos de peritonitis fue por bacterias gramnegativas compatibles con un origen gastrointestinal. Además, la frecuencia de peritonitis fue menor en los pacientes que recibieron antibiótico comparados con aquellos que no los recibieron (3.33 vs. $7.55 \%$ ). Aunque la frecuencia de la peritonitis asociada a procedimientos endoscópicos es baja (6.3\%), sigue siendo una de las complicaciones más graves para este grupo de pacientes ${ }^{55}$. Si bien los estudios no muestran significancia estadística a favor de los antibióticos profilácticos en todos los procedimientos endoscópicos, se observó una tendencia a la baja en el desarrollo de infecciones en aquellos que requirieron colonoscopia y que recibieron profilaxis.

El desarrollo de peritonitis fúngica es poco frecuente y se asocia a tasas de mortalidad del $17-44 \%$. El principal factor de riesgo para esta complicación es el uso reciente (en el último mes) de un esquema antibiótico ${ }^{49}$. 


\section{Posicionamiento}

La AMEG sugiere la administración de antibióticos profilácticos vía intraperitoneal o intravenosa, así como extracción de líquido peritoneal antes de la colonoscopia diagnóstica o terapéutica en pacientes recibiendo tratamiento con DPCA. Recomendación débil, nivel de evidencia moderado (GRADE 2B).

La AMEG no recomienda administrar antibiótico profiláctico a pacientes con DPAC que requieren endoscopia superior diagnóstica. Recomendación fuerte, nivel de evidencia bajo (GRADE 1C).

La AMEG sugiere individualizar el uso de antibióticos profilácticos en pacientes con DPAC que requieren endoscopia superior terapéutica. Recomendación débil, nivel de evidencia bajo (GRADE 2C).

\section{Pacientes con cirrosis}

Hasta el $35 \%$ de los pacientes con cirrosis desarrollan infecciones nosocomiales en comparación con el $5 \%$ observado en la población general ${ }^{16,57}$. Los procedimientos endoscópicos invasivos (p. ej., ligadura o escleroterapia endoscópica de várices esofágicas) pueden incrementar la posibilidad de infección en pacientes cirróticos ${ }^{58}$.

Un metaanálisis ${ }^{59}$ que incluyó 1,241 pacientes y que fue diseñado para evaluar los beneficios y los daños de la profilaxis antibiótica comparada con placebo o no terapia en pacientes con cirrosis y hemorragia de tubo digestivo alto (HTDA), encontró que la profilaxis antibiótica se asocia a una reducción de la mortalidad (RR: 0.79; IC 95\%: 0.63-0.98), mortalidad por infección bacteriana (RR: 0.43; IC 95\%: 0.19-0.97), infecciones bacterianas (RR: 0.35; IC 95\%: 0.26-0.47) (RR: 0.53; IC 95\%: 0.38-0.74) y días de hospitalización (RM: 1.91; IC 95\%: 3.80-0.02).

En un estudio retrospectivo ${ }^{60}$ de 235 pacientes cirróticos con hemorragia por úlcera péptica, 88 pacientes recibieron ceftriaxona profiláctica intravenosa y 147 pacientes no recibieron profilaxis. Hasta el $20.4 \%(n=48)$ experimentaron sangrado recurrente y un $19.6 \%$ ( $n=46)$ desarrollaron infecciones bacterianas. Un número significativamente mayor de pacientes presentaron infección y sangrado recurrente en el grupo sin antibiótico en comparación con el grupo con antibiótico ( 25.2 vs. $10.2 \% ; p=0.005$ y 30.6 vs. $3.4 \% ; p<0.001$, respectivamente). Los factores predictivos de riesgo para el sangrado recurrente fueron la puntuación de Rockall ( $p=0.004)$, las unidades de transfusión de sangre $(p=0.031)$ y ausencia de profilaxis con antibióticos $(p<0.001)$. Para las infecciones bacterianas fueron la puntuación de Child-Pugh $(p=0.003)$, alcoholismo activo $(p=0.035)$ y ausencia de profilaxis con antibióticos $(p=0.009)$.

La puntuación de Rockall y el sangrado recurrente fueron factores predictivos de mortalidad hospitalaria. En el análisis de subgrupos, la supervivencia se redujo significativamente en pacientes descompensados $(p=0.034)$.

\section{Posicionamiento}

La AMEG recomienda el uso de antibióticos en pacientes cirróticos con HTDA (variceal y no variceal). Esta medida disminuye la mortalidad, la frecuencia de infecciones y el sangrado recurrente. Recomendación fuerte, nivel de evidencia alta (GRADE 1A).

\section{Uso de antibióticos profilácticos durante procedimientos endoscópicos en pacientes inmunocomprometidos, con neutropenia grave y/o malignidad hematológica}

La información sobre el riesgo de complicaciones infecciosas asociadas a procedimientos endoscópicos en pacientes inmunocomprometidos y la eficacia del uso de antibióticos profilácticos para su prevención es extremadamente limitada. Los estudios publicados tienen limitaciones de diseño y tamaño de muestra; incluyen pacientes con gran heterogeneidad en cuanto a riesgos, edad y tipo de procedimiento realizado, así como uso de diferentes definiciones de infección; además de no incluir grupos control, por lo que se desconoce si el riesgo de complicaciones infecciosas asociado a procedimientos endoscópicos es mayor en personas inmunocomprometidas comparadas con poblaciones sin inmunocompromiso $0^{8,61-64}$.

La información disponible incluye únicamente estudios en pacientes con neutropenia secundaria a la administración de quimioterapéuticos para el tratamiento de neoplasias hematológicas y de órganos sólidos, incluyendo pacientes trasplantados de médula ósea y personas con anemia aplásica. No hay información sobre el riesgo de complicaciones infecciosas asociadas a procedimientos endoscópicos en personas con otras etiologías de inmunosupresión (p. ej., infección por virus de la inmunodeficiencia humana [VIH], trasplantados de órgano sólido, desnutrición, inmunodeficiencias primarias, ni de usuarios de inmunomoduladores biológicos). 
En un estudio retrospectivo realizado en un centro de referencia oncológico en la ciudad de Houston entre 2010 y $2015^{61}$ se estudiaron pacientes afebriles con neutropenia ( $<1,000$ neutrófilos/ $\mu$ l totales) en el día previo a los procedimientos que incluyeron endoscopias de bajo y alto riesgo de infección de acuerdo con la clasificación propuesta por la ASGE $^{8}$ (Tabla 3).

La mayor parte de los procedimientos $(61 \%)$ se realizaron en pacientes con neoplasias hematológicas y el $22 \%$ habían recibido un trasplante de médula ósea en los seis meses previos al procedimiento. En la mayor parte de los procedimientos $(71 \%)$ a los pacientes se les había administrado antibióticos parenterales antes del procedimiento, aunque el $91 \%$ de los pacientes con neutropenia profunda (< 200 cél./ $\mu$ l) los recibieron. La mitad de los procedimientos fueron endoscopias superiores con o sin toma de biopsia y en 41 de estas se colocaron PEG; se realizaron 35 CPRE (la mayoría con esfinterotomías pancreáticas o biliares) y 8 USE. En el $73 \%$ de los procedimientos se realizó alguna intervención endoscópica (toma de biopsias en el $48 \%$ ). En total, el $9 \%$ de los procedimientos se clasificaron de alto riesgo de infección ${ }^{61}$. Solo 24 pacientes $(4 \%)$, en 28 procedimientos endoscópicos, desarrollaron alguna complicación infecciosa en la semana siguiente al procedimiento (definida como la presencia de fiebre o infección). La frecuencia de complicaciones infecciosas fue similar en los procedimientos de alto y bajo riesgo de infección (4\%). En los 28 procedimientos en los que se desarrollaron complicaciones infecciosas, el único factor de riesgo independiente fue un pobre estado funcional (RM: 9.79; IC 95\%: 4.0923.36). El grado de neutropenia, la edad, el uso de inmunosupresores, el riesgo de los procedimientos y la presencia de fiebre en los días previos a los procedimientos no se asociaron a complicaciones infecciosas. Aunque el uso de antibióticos profilácticos mostró una tendencia a la disminución del riesgo de complicaciones infecciosas, esta reducción no fue estadísticamente significativa (RM: 0.60; IC 95\%: 0.21-1.72) . $^{61}$.

En una revisión sistemática que incluyó ocho estudios retrospectivos en pacientes con neutropenia a los que se realizó algún procedimiento endoscopio entre 1985 y 2007 solo en tres de estos estudios se reportó la frecuencia de complicaciones infecciosas posteriores a los procedimientos; esto dificulta obtener conclusiones solidas en relación a estas complicaciones, pues además únicamente se describen casos individuales de pacientes con complicaciones reportadas en cada uno de los estudios, identificando a la PEG en pacientes con neutropenia grave como el procedimiento con mayor riesgo de infecciones ${ }^{62}$.

Las guías del uso de profilaxis antibiótica del Committee of the British Society of Gastroenterology $(2009)^{63}$, de la European Society of Gastrointestinal Endoscopy (ESGE) (1998) ${ }^{64}$ y de la ASGE $(2015)^{8}$ fueron emitidas antes de la publicación de estos dos estudios. La ASGE y la ESGE evitan emitir una recomendación sobre la administración de antibióticos profilácticos en pacientes inmunosuprimidos con base en el riesgo inherente a la inmunosupresión, mientras que la sociedad británica recomienda administrar antibióticos profilácticos en pacientes con neutropenia grave (<500 cél./ $\mu$ l) o neoplasias hematológicas en estadios avanzados a los que se les realizará un procedimiento de alto riesgo de bacteriemia con el fin de evitar eventos de bacteriemia asociados al procedimiento ${ }^{63}$.

\section{Posicionamiento}

La AMEG recomienda la administración de antibióticos profilácticos a pacientes con neutropenia grave $(<1,000$ cél.//ul) afebriles a los que se les realice procedimientos endoscópicos con alto riesgo de bacteriemia y/o complicaciones infecciosas. Recomendación fuerte, nivel de la evidencia bajo (GRADE 1C).

No existe suficiente información para emitir una recomendación o sugerencia para pacientes no neutropénicos con otro tipo de inmunocompromiso (infección por VIH, trasplantados de órgano sólido, desnutrición o inmunodeficiencias primarias, ni usuarios de inmunomoduladores biológicos).

\section{Prevención de infecciones y reprocesamiento}

\section{Clasificación de equipos médicos}

La clasificación de Spaulding categoriza a los dispositivos médicos como críticos, semicríticos y no críticos según su riesgo de provocar una infección si están contaminados. Además, propone el nivel de procesamiento requerido: esterilización, desinfección de alto, intermedio y bajo nivel (DAN, DIN, DBN); basado en la naturaleza del dispositivo y en la forma en que será utilizado ${ }^{65,66}$ (Tabla 6).

\section{Dispositivos de USO CRÍtICO}

Los dispositivos de uso crítico deben ser esterilizados y solo en aquellos sensibles al calor e 
Tabla 6. Clasificación de Spaulding

\begin{tabular}{|l|l|l|}
\hline Dispositivo & Ejemplos & Nivel de procesamiento \\
\hline Uso crítico & $\begin{array}{l}\text { - Accesorios (pinza de } \\
\text { biopsias, asas de } \\
\text { polipectomía, } \\
\text { accesorios para CPRE) }\end{array}$ & - Esterilización \\
\hline $\begin{array}{l}\text { Uso } \\
\text { semicrítico }\end{array}$ & $\begin{array}{l}\text { Endoscopios y sus } \\
\text { componentes }\end{array}$ & $\begin{array}{l}\text { - Desinfección de alto } \\
\text { nivel }\end{array}$ \\
\hline $\begin{array}{l}\text { Uso no } \\
\text { crítico }\end{array}$ & - Oxímetro & $\begin{array}{l}\text { - Laumpieza manual o } \\
\text { desinfección que }\end{array}$ \\
\hline & - Estetoscopio & $\begin{array}{l}\text { alcanza al menos un } \\
\text { bactericida y fúngica }\end{array}$ \\
\hline
\end{tabular}

CPRE: colangiopancreatografía retrógrada endoscópica.

Tabla 7. Transmisión de infecciones asociadas a endoscopios. Principales gérmenes involucrados

\begin{tabular}{|l|l|l|}
\hline Bacteria & Virus & Infecciones misceláneas \\
\hline Salmonella spp. & Hepatitis B & Parásitos \\
\hline Klebsiella spp. & Hepatitis C & Hongos \\
\hline Pseudomonas & $\begin{array}{l}\text { Virus de } \\
\text { inmunodeficiencia } \\
\text { humana }\end{array}$ & $\begin{array}{l}\text { Enfermedad de } \\
\text { Creutzfeldt-Jakob (priones) }\end{array}$ \\
\hline $\begin{array}{l}\text { Helicobacter } \\
\text { pylori }\end{array}$ & & \\
\hline $\begin{array}{l}\text { Clostridium } \\
\text { difficile }\end{array}$ & & \\
\hline Micobacterias & & \\
\hline
\end{tabular}

incompatibles con los procesos de vapor, gas o plasma a baja temperatura se debe utilizar un desinfectante químico líquido.

\section{Posicionamiento}

La AMEG recomienda que los dispositivos de uso crítico (aquellos que ingresan a un tejido estéril o al sistema vascular) sean procesados mediante esterilización. Recomendación fuerte, nivel de evidencia alto (GRADE 1A).

\section{Dispositivos de uso semicrítico}

Los dispositivos semicríticos son los que entran en contacto con las mucosas intactas y que normalmente no penetran al tejido estéril. Estos dispositivos, en los que se incluyen los endoscopios gastrointestinales, deben recibir al menos $\mathrm{DAN}^{66}$. Los endoscopios flexibles primero deben limpiarse exhaustivamente y después someterse al menos a DAN, lo que se considera el estándar de atención en el reprocesamiento de los endoscopios ${ }^{67}$. Se deben enjuagar por completo los endoscopios y otros dispositivos que han sido expuestos a desinfectantes de alto nivel. La poca adherencia a las guías de limpieza, desinfección, secado y almacenamiento son factores que contribuyen a infecciones y brotes infecciosos asociados a endoscopios ${ }^{68}$.

La eficacia de los desinfectantes químicos depende de su concentración, temperatura, naturaleza física del endoscopio (grietas, bisagras, lúmenes, canales), naturaleza de los microorganismos en el endoscopio, tamaño de la carga orgánica y duración de la exposición a la solución química.

Los desinfectantes de alto nivel reutilizables deben eliminarse y reemplazarse siempre que la concentración mínima efectiva falle o la vida de reutilización expire (lo que ocurra primero), siguiendo las recomendaciones del fabricante.

\section{Posicionamiento}

La AMEG recomienda que los endoscopios sean reprocesados mediante limpieza y desinfección de alto nivel después de cada uso, siguiendo las instrucciones del fabricante y los lineamientos internacionales. Recomendación fuerte, nivel de la evidencia moderado (GRADE 1B).

\section{Dispositivos de uso no crítico}

Estos dispositivos no siempre tienen contacto con la piel o mucosa del paciente, por lo que no se requiere sean esterilizados, solo requieren una desinfección de bajo nivel.

\section{Posicionamiento}

La AMEG recomienda que los dispositivos de uso no crítico sean sometidos a una desinfección de bajo nivel. Recomendación fuerte, nivel de evidencia alto (GRADE 1A).

\section{Prevención de infecciones}

Las complicaciones infecciosas en endoscopia dependen del tipo de procedimiento y el riesgo de cada paciente. Se dividen en infecciones endógenas (infecciones derivadas de la propia flora del paciente) y exógenas (transmisión de organismos entre pacientes por equipo contaminado) (Tabla 7). 
Tabla 8. Síntesis de los posicionamientos

Procedimientos endoscópicos de alto y bajo riesgo de bacteriemia e infección

- Procedimientos endoscópicos diagnósticos de tubo digestivo

La AMEG recomienda que no se utilicen antibióticos profilácticos en los procedimientos endoscópicos diagnósticos (GRADE 1C)

- Procedimientos endoscópicos terapéuticos de tubo digestivo

La AMEG recomienda no administrar antibióticos profilácticos en pacientes a quienes se les realizara dilatación endoscópica (GRADE 1C)

La AMEG no recomienda el uso de antibióticos como profilaxis en los pacientes sometidos a tratamiento endoscópico de várices esofágicas sin sangrado (GRADE 1A)

- Riesgo de bacteriemia e infección por accesos enterales percutáneos endoscópicos

La AMEG recomienda el uso de antibióticos profilácticos de 30 a 60 minutos antes de la PEG con técnica de tracción. La selección del antibiótico dependerá de la epidemiologia hospitalaria (GRADE 1B)

- Riesgos de bacteriemia e infección asociados a CPRE

La AMEG recomienda no administrar profilaxis con antibióticos cuando se anticipa un drenaje completo de la vía biliar (GRADE 1A)

La AMEG recomienda profilaxis en pacientes sometidos a CPRE con factores de riesgo de colangitis. Deben usarse antibióticos que cubran la flora biliar gramnegativa y enterococos y continuarlos después del procedimiento si el drenaje biliar es incompleto. Se recomienda no utilizar quinolonas en profilaxis (GRADE 1B)

La AMEG recomienda antibióticos profilácticos en pacientes sometidos a colangioscopia con toma de biopsias (GRADE 1B)

- Procedimientos de USE con riesgo de bacteriemia e infección

La AMEG no recomienda el uso de antibióticos profilácticos en los casos de toma de biopsia de lesiones sólidas (GRADE 1C)

En el caso de punción de lesiones quísticas la AMEG sugiere el uso de antibióticos profilácticos. En la actualidad se sugiere no usar quinolonas con fines profilácticos (GRADE 2C)

- Riesgo de bacteriemia e infección en DES y REM

La AMEG no recomienda el uso de antibióticos profilácticos previos a la realización de DES o REM (GRADE 1B)

Condiciones médicas con riesgo incrementado de presentar bacteriemia e infección derivada de un procedimiento

endoscópico

- Endocarditis infecciosa

La AMEG no recomienda el uso de antibióticos profilácticos para endocarditis previo a un procedimiento endoscópico salvo en el caso de condiciones cardiacas como dispositivos protésicos/válvulas cardiacas (mecánicos o bioprotésicos), antecedente de endocarditis infecciosa, trasplante cardiaco, valvulopatía cardiaca y en pacientes con cardiopatía congénita (GRADE 1B)

- Prótesis ortopédicas

Dada la baja incidencia de infecciones articulares tras la endoscopia, la AMEG no recomienda los antibióticos profilácticos previo procedimiento endoscópico ante la presencia de prótesis ortopédicas (GRADE 1B)

- DPAC

En pacientes bajo DPAC, la AMEG sugiere la administración de antibióticos profilácticos vía intraperitoneal o intravenosa, así como extracción de líquido peritoneal antes de la colonoscopia diagnóstica o terapéutica (GRADE 2B)

En el caso de pacientes con DPAC que requieren endoscopia superior diagnóstica la AMEG recomienda no usar antibiótico profiláctico (GRADE 1C)

En el caso de pacientes con DPAC que requieren endoscopia superior terapéutica la AMEG sugiere individualizar en cada caso el uso de antibióticos profilácticos (GRADE 2C)

- Pacientes con cirrosis

La AMEG recomienda el uso de antibióticos en pacientes cirróticos con HTDA (variceal y no variceal). Esta medida disminuye la mortalidad, la frecuencia de infecciones y el sangrado recurrente (GRADE 1A)

- Uso de antibióticos profilácticos durante procedimientos endoscópicos en pacientes inmunocomprometidos, con neutropenia grave y/o malignidad hematológica

La AMEG recomienda que los pacientes con neutropenia grave $(<1,000$ cél./ul) afebriles a los que se les realicen procedimientos endoscópicos con alto riesgo de bacteriemia y/o complicaciones infecciosas deberán recibir antibióticos profilácticos (GRADE 1C)

Prevención de infecciones y reprocesamiento

- Clasificación de equipos médicos

La AMEG recomienda que los dispositivos de uso crítico (aquellos que ingresan a un tejido estéril o al sistema vascular) sean procesados mediante esterilización (GRADE 1A)

La AMEG recomienda que los endoscopios sean reprocesados mediante limpieza y desinfección de alto nivel después de cada uso, siguiendo las instrucciones del fabricante y los lineamientos internacionales (GRADE 1B)

La AMEG recomienda que los dispositivos de uso no crítico sean sometidos a una desinfección de bajo nivel (GRADE 1A)

- Prevención de infecciones

La AMEG recomienda el reprocesamiento adecuado de los endoscopios para evitar la transmisión de infecciones exógenas (GRADE 1A)

La AMEG recomienda no realizar una endoscopia digestiva en un paciente con sospecha o confirmación de la variante de Creutzfeldt-Jakob (GRADE 1B)

La AMEG recomienda considerar un tiempo de desinfección de alto nivel más prolongado en los endoscopios utilizados en pacientes con infección por Clostridium difficile (GRADE 1C)

AMEG: Asociación Mexicana de Endoscopia Gastrointestinal; GRADE: Grading of Recommendations, Assessment, Development and Evaluation; PEG: gastrostomía percutánea endoscópica; USE: ultrasonido endoscópico; DES: disección endoscópica submucosa; REM: resección endoscópica de la mucosa; DPAC: diálisis peritoneal continua ambulatoria; HTDA: hemorragia de tubo digestivo alto. 


\section{INFECCIONES BACTERIANAS}

Entre 1974 y 1987 se reportaron 84 casos de infección por Salmonella spp. asociados a endoscopia ${ }^{69,70}$. En el año 2011 se reportaron cuatro casos de infección asociada a endoscopia por Pseudomonas multirresistentes. Las causas identificadas fueron limpieza inicial insuficiente, acortamiento en los tiempos de cepillado e inmersión, irrigación insuficiente de canales y secado inadecuado previo al almacenamiento. Otros casos reportados por Pseudomonas se ha asociado a limpieza inadecuada del canal del elevador de los duodenoscopios, así como a cepas con resistencia al glutaraldehído ${ }^{71,72}$.

Hasta el $61 \%$ de los endoscopios se contaminan después de usarlos en pacientes con Helicobacter pylori; sin embargo, la limpieza y desinfección convencional son altamente efectivos eliminándolo ${ }^{73}$. Los reportes de infección por Klebsiella, Enterobacter, Serratia y Staphylococcus son aislados y previos al establecimiento de guías de reprocesamiento ${ }^{74,75}$.

Las directrices actuales de reprocesamiento permiten una erradicación de micobacterias, así como inactivar la biocapa (o biofilm) y esporas de Clostridium difficile ${ }^{76-78}$.

Los brotes asociados a enterobacterias resistentes a carbapenémicos se deben a los duodenoscopios en CPRE; los factores que incrementan el riesgo de infección son la colocación de endoprótesis biliar, colangiocarcinoma y una pobre condición en pacientes hospitalizados. La mayoría de los casos reportados se atribuyen a una limpieza inadecuada de la punta del duodenoscopio, en particular al canal del elevador con un cepillado inadecuado de dicha zona en la limpieza manual, que contribuye a la formación de biofilm. Actualmente ya existen duodenoscopios con la punta desmontable para una mejor técnica en su reprocesamiento ${ }^{79,80}$.

\section{INFECCIONES VIRALES}

La transmisión de infecciones virales asociada a procedimientos endoscópicos es un evento posible, pero extremadamente raro cuando se siguen los lineamientos de reprocesamiento y desinfección. En 1997 se documentaron dos casos de hepatitis $\mathrm{C}$ aguda tras la realización de colonoscopia ${ }^{81}$. Al investigar el evento, este se atribuyó a un mal reprocesamiento del equipo. Posteriormente en dos cohortes prospectivas se confirmó la eficacia del reprocesamiento mediante DAN para prevenir la transmisión y eliminar al virus de hepatitis C, incluso en grupos de alta prevalencia ${ }^{82,83}$.
También se han reportado casos de hepatitis B relacionados a procedimientos endoscópicos, sin embargo con los estándares de desinfección actual se ha logrado eliminar esta transmisión ${ }^{84}$. No se han reportado casos de infección por el VIH.

Es importante destacar que no solo los endoscopios son posibles vectores y que la transmisión de estas infecciones se ha relacionado al mal manejo de las vías intravenosas y a los medicamentos para sedación ${ }^{85}$.

\section{TRANSMISIÓN DE MICROORGANISMOS MISCELÁNEOS}

\section{Priones}

Ante la sospecha de Creutzfeldt-Jakob se debe evita la realización de procedimientos endoscópicos, pues no existe un método eficaz que elimine a los priones $^{86}$. En caso de realizar un estudio endoscópico en estos pacientes se debe considerar incinerar el endoscopio ${ }^{87}$.

\section{Clostridium difficile}

La eliminación de Clostridium spp. requiere una exposición prolongada a desinfectante de alto grado (glutaraldehído por 3 horas). Patterson reportó una posible transmisión de esta bacteria, con base en el desarrollo de colitis fulminante posterior a una colonoscopia ${ }^{88}$. Sattar, et al. reportaron que los colonoscopios y duodenoscopios que no cumplen con el proceso adecuado de descontaminación transmiten esporas de un paciente a otro ${ }^{89}$. La limpieza del equipo de endoscopia requiere la utilización de desinfectantes de alto nivel, así como una exposición prolongada a estos, para destruir a Bacillus subtilis, Clostridium sporogenes y C. difficile ${ }^{90}$.

\section{Hongos}

No existen casos documentados de transmisión de infecciones fúngicas por endoscopia ${ }^{91}$.

\section{Posicionamiento}

La AMEG recomienda el reprocesamiento adecuado de los endoscopios para evitar la transmisión de infecciones exógenas. Recomendación fuerte, nivel de evidencia alto (GRADE 1A).

La AMEG recomienda no realizar una endoscopia digestiva en un paciente con sospecha o confirmación 
de la variante de Creutzfeldt-Jakob. Recomendación fuerte, nivel de evidencia moderado (GRADE 1B).

La AMEG recomienda considerar un tiempo de desinfección de alto nivel más prolongado en los endoscopios utilizados en pacientes con infección por $C$. difficile. Recomendación fuerte, nivel de evidencia bajo (GRADE 1C).

\section{Conclusiones}

La presente guía de la AMEG sobre prevención de infecciones y uso de antibióticos profilácticos en endoscopia es el resultado de un análisis multidisciplinario basado en la evidencia disponible hasta el momento de su elaboración y en la opinión de especialistas expertos. Esta guía tiene la intención de proveer recomendaciones en puntos clave por parte de los participantes que ayuden a los médicos que ayuden a los médicos y personal de salud relacionado con el cuidado de pacientes que requieren estudios endoscópicos. La presente guía debe interpretarse e implementarse de manera individualizada y en conjunto con un equipo multidisciplinario (Tabla 8).

\section{Financiamiento}

La presente investigación no ha recibido ninguna beca específica de agencias de los sectores público, comercial, o sin ánimo de lucro.

\section{Conflicto de intereses}

Alejandra Noble Lugo es conferencista de Asofarma, Menarini, Takeda, AlfaSigma y AstraZeneca.

Los participantes no enlistados anteriormente, no enviaron declaración sobre relaciones financieras y potenciales conflictos de interés.

\section{Responsabilidades éticas}

Protección de personas y animales. Los autores declaran que para esta investigación no se han realizado experimentos en seres humanos ni en animales.

Confidencialidad de los datos. Los autores declaran que han seguido los protocolos de su centro de trabajo sobre la publicación de datos de pacientes.

Derecho a la privacidad y consentimiento informado. Los autores declaran que en este artículo no aparecen datos de pacientes.

\section{Bibliografía}

1. Fink A, Kosecoff J, Chassin M, Brook RH. Consensus methods: characteristics and guidelines for use. Am J Public Health 1984;74:979-83.

2. Grading tutorial [Internet]. UpToDate [consultado: 15 de marzo de 2017]. Disponible en: http://www.uptodate.com/home/grading-tutorial

3. Guyatt GH, Oxman AD, Vist GE, Kunz R, Falck-Ytter Y, Alonso-Coello P, et al. GRADE: an emerging consensus on rating quality of evidence and strength of recommendations. BMJ. 2008;336:924-6.

4. Giannelli V, Di Gregorio V, Lebba V, Giusto M, Schippa S, Merli M, et al. Microbiota and the gut-liver axis: Bacterial translocation, inflammation and infection in cirrhosis. World J Gastroenterol. 2014;20(45):16795-810.

5. Ponziani F, Zocco MA, Cerrito L, Gasbarrini A. Bacterial translocation in patients with liver cirrhosis: physiology, clinical consequences, and practical implications. Expert Rev Gastroenterol Hepatol. 2018;12(7):641-56.

6. Ravinder N, Hariom Y. Bacterial translocation from the gut to the distant organs: An overview. Ann Nutr Metab. 2017;71(suppl 1):11-6.

7. Wiest R, Lawson M, Geuking M. Pathological bacterial translocation in liver cirrhosis. J Hepatol. 2014;60:197-209.

8. ASGE Standards of Practice Committee, Khashab MA, Chithadi KV, Acosta RD, Bruining DH, Chandrasekhara V, Eloubeidi MA, et al. Antibiotic prophylaxis for Gl endoscopy. Gastrointest Endosc. 2015;81(1): 81-9.

9. Fernández Catón SB. Los eventos adversos y la seguridad del paciente. Boletín CONAMED - OPS n.ำ 3; nov - dic 2015.

10. ASGE Standards of Practice Committee, Ben-Menachem T, Decker GA Early DS, Evans J, Fanelli RD, Fisher DA, et al. Adverse events of upper GI endoscopy. Gastrointest Endosc. 2012;76(4):707.

11. ASGE Quality Assurance in Endoscopy Committee, Calderwood $\mathrm{AH}$, Day LW, Muthusamy VR, Collins J, Hambrick RD 3rd, Brock AS, et al. ASGE guideline for infection control during GI endoscopy. Gastrointest Endosc. 2018;87:1167-79.

12. Laboratory Biosafety Manual. Third edition [Internet]. Ginebra: World Health Organization; 2004. Disponible en: http://www.who.int/csr/resources/publications/biosafety/en/Biosafety7.pdf

13. Nelson DB. Infectious disease complications of GI endoscopy: part I, endogenous infections. Gastrointest Endosc. 2003;57:546-56.

14. Nelson DB, Sanderson SJ, Azar MM. Bacteremia with esophageal dilation. Gastrointest Endosc. 1998;48(6):563.

15. Zuccaro G Jr, Richter JE, Rice TW, Achkar E, Easley K, Lewis J, et al. Viridans streptococcal bacteremia after esophageal stricture dilation. Gastrointest Endosc. 1998;48:568-73.

16. Jia Y, Dwivedi A, Elhanafi S, Ortiz A, Othman M, Zuckerman M. Low risk of bacteremia after endoscopic variceal therapy for esophageal varices: a systematic review and meta-analysis. Endosc Int Open. 2015;3(5): E409-17.

17. McClave S, Chang WK. Complications of enteral access. Gastrointest Endosc. 2003;58:739-51.

18. Ahmad A, Mouncher A, Abdoolah R, Stenson R, Wright J, Daniels A et al. Antibiotic prophylaxis for percutaneous endoscopic gastrostomy - a prospective, randomized, double-blind trial. Aliment Pharmacol Ther. 2003;18:209-15.

19. Lipp A, Lusardi G. A systematic review of prophylactic antimicrobials in PEG placement. J Clin Nursing. 2008;18:938-48.

20. Kayal V, Harshavardhan R, Rama V. Percutaneous endoscopic gastrostomy site infections - Incidence and risk factors. Indian J Gastroenterol. 2018;37:103-7.

21. Harris A, Chan AC, Torres-Viera C, Hammett R, Carr-Locke D. Meta-analysis of antibiotic prophylaxis in endoscopic retrograde cholangiopancreatography (ERCP). Endoscopy. 1999;31:718-24.

22. Brand M, Bizos D, O'Farrell P. Antibiotic prophylaxis for patients undergoing elective endoscopic retrograde cholangiopancreatography. Cochrane Database Syst Rev. 2010;10:CD007345.

23. Cotton $P$, Connor P, Rawls E, Romagnuolo J. Infection after ERCP, and antibiotic prophylaxis: a sequential quality-improvement approach over 11 years. Gastrointest Endosc. 2008;67:471-5.

24. Ismail $S$, Kylänpää L, Mustonen $H$, Halttunen J, Lindström $O$, Jokelainen $\mathrm{K}$, et al. Risk factors for complications of ERCP in primary sclerosing cholangitis. Endoscopy. 2012;44:1133-8.

25. Othman M, Guerrero R, Elfhanafi S, Davis B, Hernandez J, Houle J, et al. A prospective study of the risk of bacteremia in directed cholangioscopic examination of the common bile duct. Gastrointest Endosc. 2016;83:151-7.

26. Wang KX, Ben QW, Jin ZD, Du YQ, Zou DW, Liao Z, et al. Assessment of morbidity and mortality associated with EUS-guided FNA: a systematic review. Gastrointest Endosc. 2011;73:283-90.

27. Banafea O, Mghanga FP, Zhao J, Zhao R, Zhu L. Endoscopic ultrasonography with fine-needle aspiration for histological diagnosis of solid pancreatic masses: a meta-analysis of diagnostic accuracy studies. BMC Gastroenterol. 2016;16:108.

28. Levy MJ, Abu Dayyeh BK, Fujii LL, Boardman LA, Clain JE, lyer PG, et al. Prospective evaluation of adverse events following lower gastrointestinal tract EUS FNA. Am J Gastroenterol. 2014;109:676-85. 
29. Marinos E, Lee S, Jones B, Corte C, Kwok A, Leong RW. Outcomes of single-dose peri-procedural antibiotic prophylaxis for endoscopic ultrasound-guided fine needle aspiration of pancreatic cystic lesions. United European Gastroenterol J. 2014;2:391-6.

30. Zhu H, Jiang F, Zhu J, Du Y, Jin Z, Li Z. Assessment of morbidity and mortality associated with endoscopic ultrasound-guided fine-needle aspiration for pancreatic cystic lesions: a systematic review and meta-analysis. Dig Endosc. 2017;29:667-75

31. Klein A, Qi R, Nagubandi S, Lee E, Kwan V. Single-dose intra-procedural ceftriaxone during endoscopic ultrasound fine-needle aspiration of pancreatic cysts is safe and effective: results from a single tertiary center. Ann Gastroenterol. 2017;30:237-41.

32. Guarner-Argente C, Shah P, Buchner A, Ahmad NA, Kochman ML, Ginsberg GG. Use of antimicrobials for EUS-guided FNA of pancreatic cysts: a retrospective, comparative analysis. Gastrointest Endosc. 2011;74:81-6

33. Survey of medical care activities in public health insurance in 2015 [Internet]. The Japanese Ministry of Health, Labour and Welfare; 2016. Disponible en: https://www.mhlw.go.jp/english/new-info/2015.html

34. Murata A, Muramatsu K, Ichimiya Y, Kubo T, Fujino Y, Matsuda S. Endoscopic submucosal dissection for gastric cancer in elderly Japanese patients: an observational study of financial costs of treatment based on a national administrative database. J Dig Dis. 2014;15:62-70.

35. Lee TH, Hsueh PR, Yeh WC, Wang HP, Wang TH, Lin JT. Low frequency of bacteremia after endoscopic mucosal resection. Gastrointest Endosc. 2000;52:223-5.

36. Min BH, Chang DK, Kim D, Kim YH, Rhee PL, Kim JJ, et al. Low frequency of bacteremia after an endoscopic resection for large colorectal tumors in spite of extensive submucosal exposure. Gastrointest Endosc. 2008;68:105-10

37. Itaba S, Iboshi Y, Nakamura K, Ogino H, Sumida Y, Aso A, et al. Low-frequency of bacteremia after endoscopic submucosal dissection of the stomach. Dig Endosc. 2011;23:69-72.

38. Doyama H, Yamada S, Kaneko Y. Complications associated with esophageal, gastric and colorectal ESD. Gastroenterol Endosc. 2009;51(Suppl 2):2085

39. Wilson W, Taubert KA, Gewitz M, Lockhart PB, Baddour LM, Levison M, et al. Prevention of infective endocarditis: guidelines from the American Heart Association: a guideline from the American Heart Association Rheumatic Fever, Endocarditis, and Kawasaki Disease Committee, Council on Cardiovascular Disease in the Young, and the Council on Clinical Cardiology, Council on Cardiovascular Surgery and Anesthesia, and the Quality of Care and Outcomes Research Interdisciplinary Working Group. Circulation. 2007;116:1736-54.

40. Roduit J, Jornod P, Dorta N, Blum AL, Dorta G. Antibiotic prophylaxis of infective endocarditis during digestive endoscopy: over- and underuse in Switzerland despite professed adherence to guidelines. Endoscopy. 2002;34(4):322-4.

41. Siegman-Igra Y. Infective endocarditis following gastrointestinal and genitourinary procedures: an argument in favour of prophylaxis. Scand $J$ Infect Dis. 2010;42(3):208-14.

42. García-Albéniz X, Hsu J, Lipsitch M, Bretthauer M, Logan RW, Hernández-Díaz S, et al. Colonoscopy and risk of infective endocarditis in the elderly. J Am Coll Cardiol. 2016;68(5):570-1.

43. Thomsen RW, Farkas DK, Friis S, Sværke C, Ording AG, Nørgaard M, et al. Endocarditis and risk of cancer: A Danish nationwide cohort study. Am J Med. 2013;126(1):58-67.

44. Pritchard T, Foust R, Cantey R. Prosthetic valve endocarditis due to Cardiobacterium hominis occurring after upper gastrointestinal endoscopy. Am J Med. 1991:90:516-8.

45. Coelho-Prabhu N, Oxentenko AS, Osmon DR, Baron Todd H, Hanssen AD, Wilson WR, et al. Increased risk of prosthetic joint infection associated with esophago-gastro-duodenoscopy with biopsy. Acta Orthop. 2013;84(1):82-6.

46. Ainscow DA, Denham RA. The risk of haematogenous infection in tota joint replacements. J Bone Joint Surg Br. 1984;66(4):580-2.

47. DeFroda SF, Lamin E, Gil JA, Sindhu K, Ritterman S. Antibiotic prophylaxis for patients with a history of total joint replacement. J Am Board Fam Med. 2016;29(4):500-7.

48. Gould AM, Chahl E, Hachem C. Peritonitis following endoscopy in a patient on peritoneal dialysis with a discussion of current recommendations on antibiotic prophylaxis. Case Rep Gastroenterol. 2015;9:302-6.

49. Dhruve MJ, Bargman JM. Antibiotic prophylaxis in peritoneal dialysis patients. Adv Perit Dial. 2017:33:55-8.

50. Priano B, Bernardini J, Brown E, Figueiredo A, Johnson DW, Lye WC, et al. ISPD position statement on reducing the risks of peritoral dialysis-related infections. Perit Dial Int. 2011:31:614-30.

51. Li PK, Szeto CC, Piraino B, de Arteaga J, Fan S, Figueiredo AE, et al. ISPD peritonitis recommendations: 2016 update on prevention and treatment. Perit Dial Int. 2016:36:481-508.

52. Lin JN, Wang CB, Yang CH, Lai CH, Lin HH. Risk of infection following colonoscopy and sigmoidoscopy in symptomatic patients. Endoscopy. 2017;49:574-764.
53. Yip T, Tse KC, Lam MF, Cheng SW, Lui SL, Tang S, et al. Risks and outcomes of peritonitis after flexible colonoscopy in CAPD patients. Perit Dial Int. 2007;27:560-4.

54. Warady BA, Bakkaloglu S, Newland J, Cantwell M, Verrina E, Neu A, et al. Consensus guidelines for the prevention and treatment of catheter-related infections and peritonitis in pediatric patients receiving peritoneal dialysis: 2012 update. Perit Dial Int. 2012;32(Suppl 2):S32-S86.

55. Wu HH, Li IJ, Weng CH, Lee CC, Chen YC, Chang MY, et al. Prophylactic antibiotics for endoscopy-associated peritonitis in peritoneal dialysis patients. PLoS One. 2013;8:e71532.

56. Al-Hwiesh AK, Abdul-Rahman IS, Hussameldeen MA, Al-Audah N, Abdelrahman A, Moaigel HM, et al. Colonoscopy in automated peritoneal dialysis patients: value of prophylactic antibiotics: a prospectivestudy on a single antibiotic. Int J Artif Organs. 2017:40:550-7.

57. Maimone S, Saffioti F, Filomia R, Caccamo G, Saitta C, Pallio S, et al. Elective endoscopic variceal ligation is not a risk factor for bacterial infection in patients with liver cirrhosis. Dig Liver Dis. 2018;50(4):366-9.

58. Zuckerman MJ, Jia Y, Hernandez JA, Kolli VR, Norte A, Amin H, et al. A Prospective randomized study on the risk of bacteremia in banding versus sclerotherapy of esophageal varices. Front Med (Lausanne). 2016;3:16.

59. Chavez-Tapia NC, Barrientos-Gutierrez T, Tellez-Avila F, Soares-Weiser K, Mendez-Sanchez N, Gluud C, et al. Meta-analysis: antibiotic prophylaxis for cirrhotic patients with upper gastrointestinal bleeding - an updated Cochrane review. Aliment Pharmacol Ther. 2011;34(5):509-18

60. Kuo MT, Yang SC, Lu LS, Hsu CN, Kuo YH, Kuo CH, et al. Predicting risk factors for rebleeding, infections, mortality following peptic ulcer bleeding in patients with cirrhosis and the impact of antibiotics prophylaxis at different clinical stages of the disease. BMC Gastroenterol. 2015;15:61.

61. Abu-Sbeih H, Ali FS, Coronel E, Chen HC, Wang X, Lum P, et al. Safety of endoscopy in cancer patients with thrombocytopenia and neutropenia. Gastrointest Endosc. 2019;89(5):937-49.e2.

62. Tong MC, Tadros M, Vaziri H. Endoscopy in neutropenic and/or thrombocytopenic patients. World J Gastroenterol. 2015;21(46):13166-76.

63. Allison MC, Sandoe JA, Tighe R, Simpson IA, Hall RJ, Elliott TS; Endoscopy Committee of the British Society of Gastroenterology. Antibiotic prophylaxis in gastrointestinal endoscopy. Gut. 2009;58(6):869-80.

64. Rey JR, Axon A, Budzynska A, Kruse A, Nowak A; Working Group of the European Society of Gastrointestinal Endoscopy. Guidelines of the European Society of Gastrointestinal Endoscopy. Endoscopy. 1998:30:318-24

65. Block SS. Disinfection, sterilization and preservation, 5th ed. Lippincott Williams \& Wilkins; 2001. pp. 21-22.

66. Reprocessing Guideline Task Force; Petersen BT, Cohen J, Hambrick 3rd RD, Buttar N, Greenwald DA, Buscaglia JM, et al. Multisociety guideline on reprocessing flexible Gl endoscopes: 2016 update. Gastrointest Endosc. 2017:85(2):282-94.

67. Society of Gastroenterology Nurses and Associates, Inc Guideline for use of high-level disinfectants \& sterilants in the gastroenterology setting. Gastroenterol Nurs. 2000;23(4):180-7.

68. McCafferty CE, Aghajani MJ, Abi-Hanna D, Gosbell IB, Jensen SO. An update on gastrointestinal endoscopy-associated infections and their contributing factors. Ann Clin Microbiol Antimicrob. 2018;17(1):36.

69. Holmberg SD, Osterholm MT, Senger KA, Cohen ML. Drug-resistant Salmonella from animals fed antimicrobials. N Engl J Med. 1984;311:617-22.

70. Dwyer DM, Klein EG, Istre GR, Robinson MG, Neumann DA, McCoy GA. Salmonella newport infections transmitted by fiberoptic colonoscopy. Gastrointest Endosc. 1987;33:84-7.

71. Bajolet O, Ciocan D, Vallet C, de Champs C, Vernet-Garnier V, Guillard T, et al. Gastroscopy-associated transmission of extended-spectrum beta-lactamase-producing Pseudomonas aeruginosa. J Hosp Infect. 2013;83:341-3.

72. Qiu L, Zhou Z, Liu Q, Ni Y, Zhao F, Cheng H. Investigating the failure of repeated standard cleaning and disinfection of a Pseudomonas aeruginosa-infected pancreatic and biliary endoscope. Am J Infect Control. 2015;43:e43-6.

73. Fantry GT, Zheng QX, James SP. Conventional cleaning and disinfection techniques eliminate the risk of endoscopic transmission of Helicobacter pylori. Am J Gastroenterol. 1995;90:227-32.

74. Parker HW, Geenen JE, Bjork JT, Stewart ET. A prospective analysis of fever and bacteremia following ERCP. Gastrointest Endosc. 1979;25:102-3.

75. Gorse GJ, Messner RL. Infection control practices in gastrointestinal endoscopy in the United States: a national survey. Infect Control Hosp Epidemiol. 1991;12:289-96.

76. Muscarella LF. Automatic flexible endoscope reprocessors. Gastrointest Endosc Clin N Am. 2000;10:245-57.

77. Muscarella LF. Evaluation of the risk of transmission of bacterial biofilms and Clostridium difficile during gastrointestinal endoscopy. Gastroenterol Nurs. 2010:33:28-35

78. Carbonne A, Thiolet JM, Fournier S, Fortineau N, Kassis-Chikhani N, Boytchev I, et al. Control of a multi-hospital outbreak of KPC-producing 
Klebsiella pneumoniae type 2 in France, September to October 2009. Euro Surveill. 2010;15:pii:19734.

79. Epstein L, Hunter JC, Arwady MA, Tsai V, Stein L, Gribogiannis M, et al. New Delhi metallo-beta-lactamase-producing carbapenem-resistant Escherichia coli associated with exposure to duodenoscopes. JAMA 2014;312:1447-55.

80. Alrabaa SF, Nguyen P, Sanderson R, Baluch A, Sandin RL, Kelker D, et al. Early identification and control of carbapenemase-producing Klebsiella pneumoniae, originating from contaminated endoscopic equipment. Am J Infect Control. 2013;41:562-4.

81. Bronowicki JP, Venard V, Botte C, Monhoven N, Gastin I, Choné L, et al. Patient-to-patient transmission of hepatitis $\mathrm{C}$ virus during colonoscopy. N Engl J Med. 1997;337:237-40.

82. Ciancio A, Manzini P, Castagno F, D'Antico S, Reynaudo P, Coucourde L, et al. Digestive endoscopy is not a major risk factor for transmitting hepatitis C virus. Ann Intern Med. 2005;142:903-9.

83. Mikhail NN, Lewis DL, Omar N, Taha H, El-Badawy A, Abdel-Mawgoud N et al. Prospective study of crossinfection from upper-Gl endoscopy in a hepatitis C-prevalent population. Gastrointest Endosc. 2007;65: 584-8.

84. Birnie GG, Quigley EM, Clements GB, Follet EA, Watkinson G. Endoscopic transmission of hepatitis B virus. Gut. 1983;24:171-4.
85. Nelson DB, Muscarella LF. Current issues in endoscope reprocessing and infection control during gastrointestinal endoscopy. World J Gastroenterol. 2006;12(25):3953-64.

86. Axon ATR, Beilenhoff M, Bramble MG, Ghosh S, Kruse A, McDonnell GE et al. Variant Creutzfeldt-Jackob disease and gastrointestinal endoscopy. Endoscopy. 2001;33(12):1070-80.

87. Kovaleva J, Peters TMF. Transmission of infection by flexible gastrointestinal ensdoscopy and bronchoscopy. Clin Microbiol Rev. 2013;26(2):231-54

88. Patterson DJ, Johnson EH, Schmulen AC. Fulminant pseudomembranous colitis ocurring after colonoscopy. Gastrointestinal Endosc. 1984; 30(4):249-53.

89. Sattar SA. Kibbee RJ, Tetro JA, Rook TA. Experimental evaluation of an automated endoscope reprocessor with in situ generation of peracetic acid for disinfection of semicritical devices. Infect Control Hosp Epidemiol. 2006;27(11):1193-9.

90. Muscarella FL. Evaluation of the risk of transmission of bacterial biofilms and clostridium difficile during gastrointestinal endoscopy. Gastroenterol Nurs. 2010;33(1):28-35.

91. ASGE Quality Assurance in Endoscopy Committee, Calderwood AH, Day LW, Muthusamy VR, Collins J, Hambrick RD 3rd, Brock AS, et al. ASGE guideline for infection control during GI endoscopy. Gastrointest Endosc. 2018;87(5):1167-79. 